\title{
Rapunzel Syndrome in a Seven-Year-Old Girl
}

\author{
Aviral Gupta $^{1,2,3,4}$ (D) Sarvesh C. Mishra ${ }^{1,2,3} \cdot$ Vijay D. Upadhyay ${ }^{1,2,3} \cdot$ Pujana Kanneganti ${ }^{1,2,3}$
}

Received: 3 February 2021 / Accepted: 12 February 2021 / Published online: 27 February 2021

(C) The Author(s) 2021

\begin{abstract}
Rapunzel syndrome is a rare entity with less than hundred case reports cited in the literature. In this, there is presence of a trichobezoar in the stomach which extends into the small intestine or beyond. It can typically cause abdominal pain and nausea, but can also present as an asymptomatic abdominal mass, progressing to abdominal obstruction and perforation. Many of these patients have associated psychiatric disorder. The gold standard for diagnosis is upper gastrointestinal endoscopy and treatment is surgical removal. Herein, we present surgical images of Rapunzel syndrome in a seven-year-old girl.
\end{abstract}

Keywords Rapunzel syndrome $\cdot$ Young girl $\cdot$ Psychiatric disorder

A seven-year-old girl presented to us with early satiety, abdominal distension, and loss of weight. There was a history of hair eating; however, there was no history of vomiting, fever, or diarrhea. On examination, there was a firm well-defined lump palpable in the left hypochondrium of size $3.5 \mathrm{~cm}$. Computerized tomography (Fig. 1) was done with concern of a possible tumor. It showed presence of well-defined intraluminal heterogenous mass with mottled appearance present in the stomach and extending into the duodenum (D4). Upper gastrointestinal endoscopy confirmed the mass as trichobezoar. The patient underwent explorative laparotomy and anterior gastrotomy where trichobezoar was removed en bloc (Fig. 2). Histopathology showed hair bundles along

Aviral Gupta

aviralguptamed@gmail.com

1 Department of Pathology, Sanjay Gandhi Post-Graduate Institute of Medical Sciences, Lucknow, Uttar Pradesh, India

2 Department of Radiodiagnosis, Sanjay Gandhi Post-Graduate Institute of Medical Sciences, Lucknow, Uttar Pradesh, India

3 Department of Pediatric Surgical Superspecialities, Sanjay Gandhi Post-Graduate Institute of Medical Sciences, Lucknow, Uttar Pradesh, India

4 Lucknow, India with vegetative material, decaying necrotic material, and many thin-walled fungal hyphae with acute angle branching. The patient was allowed orally after four days and discharged after seven days. Parents were counselled to get psychiatric consultation for the patient to prevent recurrence. Bezoars are concretions in the gastrointestinal tract that increase in size by continuous accumulation of non-absorbable food or fibers. Most common bezoars in children are trichobezoars formed by swallowed hair from the head, dolls, or brushes. Hair being slippery evades peristalsis and gets entrapped in gastric mucosal folds. More and more hair conglomerate to form a stomach-shaped mass coated with mucus called trichobezoar [1]. This provides a shiny glistening surface, and the gastric acid denatures the hair protein giving it the typical black color [2]. Trichobezoars typically cause abdominal pain and nausea, but can also present as an asymptomatic abdominal mass, progressing to abdominal obstruction and perforation. Rarely bezoar may extend from the stomach to the small intestine or beyond and is described as Rapunzel syndrome. The name "Rapunzel" syndrome comes from the Grimm Brothers' fairy tale of a twelve-year-old princess who was shut into a tower with neither stairs nor doors by an enchantress who climbed up the tower's walls with the help of Rapunzel's long tresses [3]. When a bezoar is suspected, the history should focus on trichotillomania and ingestion of items, such as doll or pet hair. Severe halitosis and patchy alopecia provide clues on physical examination [4]. Imaging may show the bezoar as a 

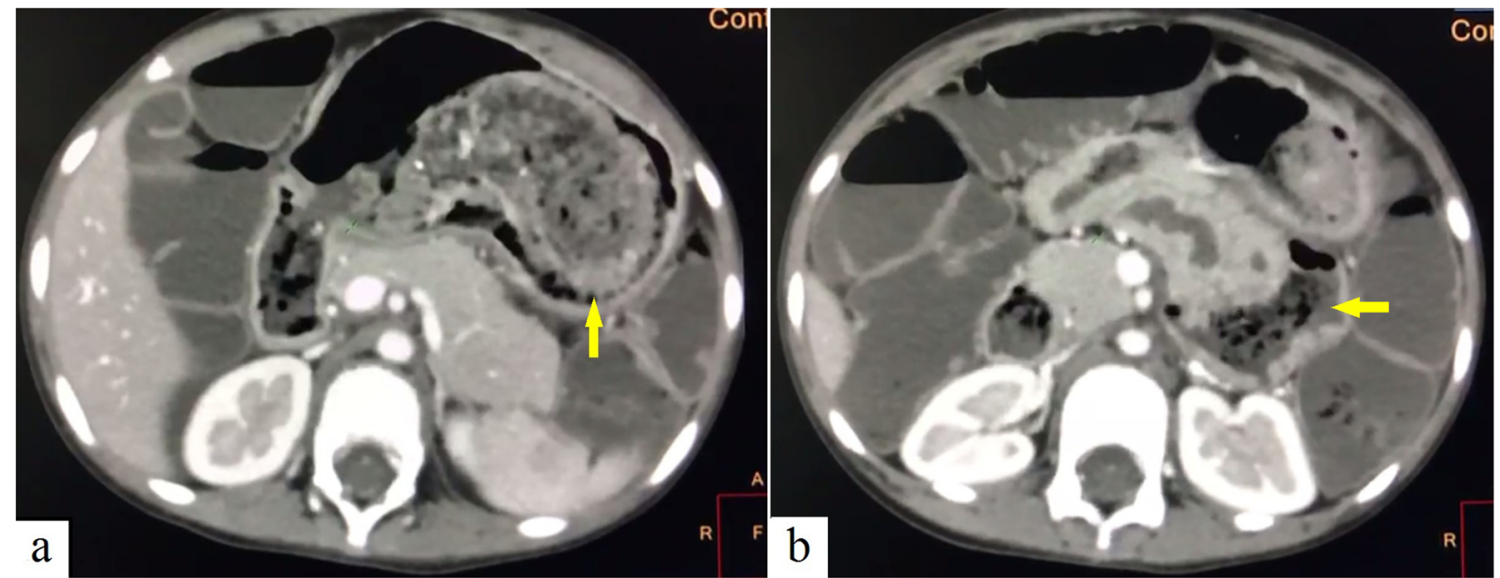

Fig. 1 Contrast computerized tomography of the abdomen shows trichobezoar appearing as a large heterogenously enhancing intraluminal mass in the stomach (a) and extending into the fourth part of the duodenum (b)

mass or filling defect. The gold standard for diagnosis is upper gastrointestinal endoscopy. The management and treatment of a Rapunzel syndrome encompass surgical removal of the mass and prevention of recurrence by addressing the underlying psychiatric disorder. Surgical removal is accomplished by gastrotomy or enterotomy.

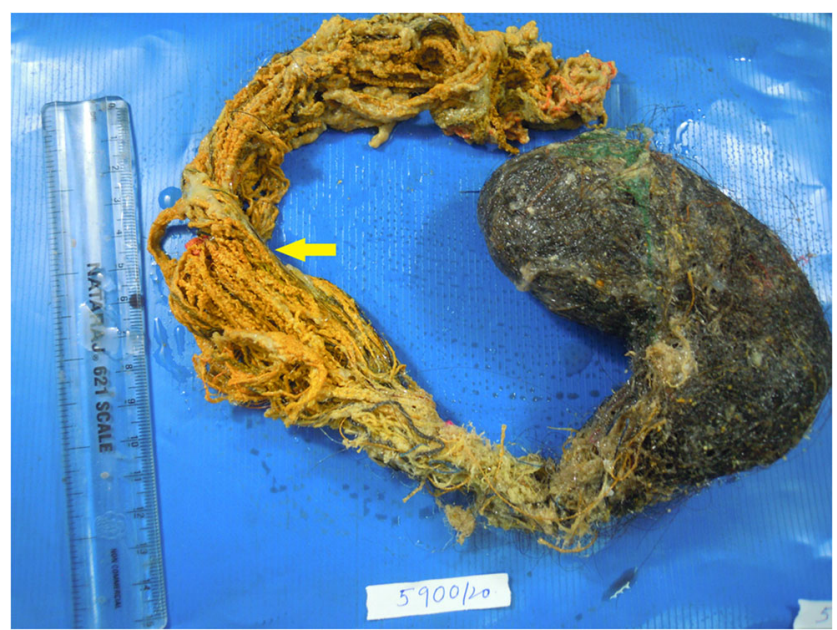

Fig. 2 Trichobezoar after surgical removal. Note that the tail end is stained with bile

\section{Declarations}

Informed Consent The present article does not mention any patient or patient details and hence, formal ethical approval or informed consent is not required.

Competing Interests The authors declare no competing interests.
Open Access This article is licensed under a Creative Commons Attribution 4.0 International License, which permits use, sharing, adaptation, distribution and reproduction in any medium or format, as long as you give appropriate credit to the original author(s) and the source, provide a link to the Creative Commons licence, and indicate if changes were made. The images or other third party material in this article are included in the article's Creative Commons licence, unless indicated otherwise in a credit line to the material. If material is not included in the article's Creative Commons licence and your intended use is not permitted by statutory regulation or exceeds the permitted use, you will need to obtain permission directly from the copyright holder. To view a copy of this licence, visit http://creativecommons.org/licenses/by/4.0/.

\section{References}

1. Pace AP, Fearne C (2003) Trichobezoar in a 13 year old male: a case report and review of literature. Malta Med J 15:39-40

2. Sharma V, Sahi RP, Misra NC (1991) Gastro-intestinal bezoars. J Indian Med Assoc 89:338-339

3. Grimm Brothers: Rapunzel. Translated by Godwin-Jones R. Richmond, Virginia Commonwealth University Department of Foreign Languages, 1994-1999.

4. Sidhu BS, Singh G, Khanna S (1993) Trichobezoar. J Indian Med Assoc 91:100-101

Publisher's Note Springer Nature remains neutral with regard to jurisdictional claims in published maps and institutional affiliations. 